\title{
PAPER PRESENTED AT IAPRI WORLD CONFERENCE 2012 Studying the Influence of Packaging Design on Consumer Perceptions (of Dairy Products) Using Categorizing and Perceptual Mapping
}

\author{
By M. M. Gelici-Zeko, ${ }^{1 *}$ D. Lutters, ${ }^{1}$ R. ten Klooster ${ }^{1}$ and P. L. G. Weijzen ${ }^{2}$ \\ ${ }^{1}$ Laboratory for Design, Production and Management, Faculty of Engineering Technology, University of Twente, \\ Drienerlolaan 5, 7522 NB, Enschede, The Netherlands \\ ${ }^{2}$ Sensory Science, Research and Development, FrieslandCampina, Deventer, The Netherlands
}

\begin{abstract}
Food packaging plays an important role in attracting consumers' attention and generating expectations in the consumer that in turn affect their product perception and buying behaviour. In the present study, 'categorizing' and 'perceptual mapping' - diametrically opposed methods (predefined criteria vs consumer criteria) — were used to study the influence of packaging design on consumer perceptions of dairy products. Eighty-nine images of milk, yoghurt and yoghurt drink with different graphical designs, sizes, shapes and materials were presented to the participants. The participants were randomly divided in two groups, each of which evaluated the samples using one method: categorizing or perceptual mapping. Both categorizing and perceptual mapping have been demonstrated to be useful, simple and user-friendly methods to determine the packaging design cues that influence the perception of dairy products. However, perceptual mapping provided more subconscious perceptions than the categorizing task. The results of perceptual mapping are objective and provide representative information. Furthermore, it fosters better understanding of the potential for product packaging to be misinterpreted and supports packaging designers in developing packages that better align with consumer perception. Copyright $\odot 2012$ John Wiley \& Sons, Ltd.
\end{abstract}

Received 12 December 2011; Revised 3 April 2012; Accepted 26 April 2012

KEY WORDS: new product development; packaging design; dairy products; perceptual mapping; categorizing

\section{INTRODUCTION}

The study of how consumers select food (packaging) in supermarkets is a complex process that is determined by several factors, including sensory and nonsensory attributes. Sensory attributes seems to have an enormous influence on the overall perception and acceptance of a food product. ${ }^{1}$ However, sensory attributes seem not to be enough to meet consumers' requirements in the context of today's highly competitive marketing environments. Nonsensory factors such as packaging and labelling also play an important role in affecting consumers' purchase decisions. ${ }^{2,3}$ This is caused by the fact that the appearance of a product can have a subsequent influence on flavour perception and food acceptability. ${ }^{4,5}$ Various studies have shown that packaging has an enormous influence on consumer perceptions, purchase decisions and food acceptance. ${ }^{6-8}$

\footnotetext{
* Correspondence to: M. M. Gelici-Zeko, Laboratory for Design, Production and Management, Faculty of Engineering Technology, University of Twente, Drienerlolaan 5, 7522 NB Enschede, The Netherlands.

E-mail: m.m.gelici-zeko@ctw.utwente.nl
} 
Nowadays, food packaging is more than a protective cover that facilitates the storage and transportation of products. Currently, the importance of these tactical functionalities can be considered to be a basic condition for all packaging. ${ }^{9}$ In the current self-service economy, packaging provides manufacturers with opportunities to persuade people to buy a product before brand selection occurs. ${ }^{10,11}$ As a consequence, packaging has become an extremely powerful and unique tool in modern marketing environments. Some marketers believe that packaging is more powerful in influencing consumers than advertising or other marketing tools. The reason for this is that packaging is a tool that is experienced by all buyers by definition and thus has a strong potential to engage most the target market. ${ }^{6,12}$ Consumers draw important information about the product and its attributes form the package's aesthetic and graphic design. ${ }^{13}$ This suggests the ability to persuade people at point of purchase, although that competitive environment is a challenging one. The importance of communicating appropriate product and brand signals on packaging is considerable as well as achieving the level of visual stand out. ${ }^{13}$

Consequently, manufacturers can use packaging design to generate appropriate expectations in the consumer regarding the product and the brand, which in turn will affect consumers' product perception and purchase decisions. ${ }^{14}$ Expectations could be regarded as pretrial beliefs about a product, affecting decisions both consciously and subconsciously. ${ }^{15-17}$ Expectations are also created through consumers' previous experiences with the product, price and store in which the product is bought. ${ }^{18-20}$ However, packaging plays a major role in generating expectations about products. Expectations emerge from packaging design cues such as colours, words, symbols, materials, shapes and images. ${ }^{18,19}$ Thus, cues on packaging may carry specific semiotic significance. ${ }^{8,21-25}$

Nevertheless, a mismatch between expectations raised by packaging design or information on the label and the actual perceived characteristics of the product would lead to positive or negative attitudes toward the product, depending if the product is better or worse than expected. ${ }^{16,26}$ This underlines the major importance which packaging design or label about the product has, rather than the properties of the product itself, and will have in the future on consumer acceptance of food products. However, this does not mean that the properties of the product, especially its sensory properties, become unimportant. ${ }^{20}$

Consequently, all packaging design cues should be deeply regarded in the design process to attract consumers' attention to generate expectations that match the product's real characteristics and to increase their interest in buying the product. ${ }^{27}$

Therefore, it is important to understand how consumers perceive products on the basis of packaging design to identify which packaging design cues are relevant, which packaging design cues can influence the perception of consumers' regarding food products and what information they will expect to see on packaging. The identification of cues might offer possibilities to design packaging that stand out and communicate in an appealing and effective way and that closely matches consumer needs and expectations, thus contributing to consumer product satisfaction.

However, in practice, a great majority of product/packaging combinations that enter the market place face very high failure rates. ${ }^{28,29}$ Yet, there are several reasons why the development of product/packaging combinations does not inherently leads to success. First, the product must be suitable for the market in which it is introduced. Often, marketers do not know or understand the market enough to be market oriented; marketers have little insight in consumer needs and preferences.

Second, food product/packaging development is hampered by the lack of research that is available to underpin decisions and by inappropriate research methods for testing new or altered food products. ${ }^{30}$ The studies that are available primarily address the influence of product/packaging design on consumer decision making, based on demand-oriented research techniques in controlled field experiments. Consequently, consumer perceptions and accompanying design cues described in literature can be used in design practice; however, they do not reflect how consumers perceive products by themselves based on packaging design. ${ }^{31,32}$

Yet, it cannot be presumed that consumers' perception of products based on predefined demandoriented criteria corresponds to how consumers actually perceive food products with packaging design. ${ }^{33}$ The appearance attributes mentioned in the literature might not give an accurate overview of how consumers themselves perceive products and the contribution of packaging design to this. ${ }^{34}$ In the light of the previous discussion, two research methods are used, and the results are compared. These methods are diametrically opposed: categorizing and perceptual mapping. 
Although both methods are widely used, no research has focused systematically on comparing the results of categorization and perceptual mapping for the identification of ideal product appeal based on consumers' perception (predefined criteria vs consumer criteria) of product packaging. In the research described in this publication, the applicability of categorization and perceptual mapping and the comparison of the results of both techniques were evaluated.

A categorization task is a method that can be used to identify appearance attributes, as people normally categorize objects they see to make sense of them. ${ }^{35}$ For the categorization task, participants are provided with a list of predefined appearance attributes in which they are asked to categorize products in terms of specific attributes based on the design of the package. Although this approach can yield interesting and useful information, it has some drawbacks. Examples are the fact that consumers can describe/perceive products differently and that a researcher can take into account criteria (appearance attributes) that may be irrelevant to the consumer. Regarding this method, results are obviously strongly dependent on the predefined attributes selected for the study. ${ }^{36}$

Alternatively, perceptual mapping is a method that requires consumers to describe/judge products according to their own criteria. Perceptual mapping is a simple, user-friendly technique that is widely used for defining perceptual differences in sets of products. The perceived differences emerge by letting consumers compare the products in a set and asking them to indicate to what extent these products are (dis)similar based on appearance of the package. Consumers are asked to denominate the aspects that explain the differences to them. The result of this technique is a so-called perceptual map. ${ }^{37}$ This technique might be a useful and simple way to evaluate consumer perception of food product on the base of packaging design in an objective way.

Subsequently, other variables than packaging design may also contribute in influencing consumer perception. Variables such as previous experiences and personal characteristics are not included in this study. However, one cannot ensure that these types of variables have no effect on consumers' perception. The study presented in this article will first discuss whether there are any differences in consumer perceptions based on packaging design when using diametrically opposed techniques. In the future, variables such as previous experience can be incorporated and tested against product perception.

The aims of the present work were (i) to identify the most important packaging cues that affect consumer perception of food products and (ii) to compare results from both methods.

\section{METHODOLOGY AND EXPERIMENTAL SETUP}

\section{Stimuli}

The selected product category for the present study was 'dairy'. This selection was made considering that these products are widely consumed in the Netherlands by several groups of consumers, including children and elderly people. Only five countries in the world consume more milk and other dairy products than Dutch people. Each Dutch consumer consumes at least one to two glasses milk or dairy portions per day. ${ }^{38}$ Besides, in terms of new product launches and developments, the dairy drinks market in the Netherlands is currently one of the most dynamic.

The selected products from the product category 'dairy' for the study were milk, yoghurt and yoghurt drink. As the sensory difference between the selected products per product group (milk, yoghurt and yoghurt drink) are relatively small, one can be confident that any differences in the perception of the product, based on visual exposure to packaging, are the result of differences in packaging design cues. The product group's milk, yoghurt and yoghurt drink consist of at least 32 different brands.

Next to that, approximately $74.3 \%$ of all dairy product packaging available in the Dutch supermarkets use laminated cardboard. ${ }^{39}$ This means that many brands compete in the field of graphic design. Producers pay a lot of attention to labelling and packaging design to capture the attention of the consumer, to generate appropriate expectations regarding the product and to persuade them to buy the product before brand selection. All product packaging scream for attention and they all communicate to be better, healthier and tastier than the competition. In addition, there is an increasing marketing activity regarding dairy products, as most dairy companies have launched low-fat and low-calorie products. 
The types of milk, yoghurt and yoghurt drink considered in the present study were all available brands sold in different Dutch supermarkets and healthy food and specialty shops. The selected packaging was from leading brands, inferior brands and private labels. When available, different variants of each product packaging were selected, from full fat to low fat, from sterilized to semi-skimmed, from perishable to not perishable and from fair trade to organic, all with different graphical packaging designs.

Although a large part of dairy packaging is packaged in laminated cardboard, for the study, samples were also selected based on structural design in which other materials and shapes were used. Next to that, the types of packaging with same graphical designs but in different structural packaging (e.g. with another material and/or shape) were chosen to compare the influence of structural and graphical design on consumer perception.

The abovementioned selection criteria resulted in a broad selection of commercial dairy samples $(n=89)$ : milk $(n=35)$, yoghurt $(n=28)$ and yoghurt drink $(n=26)$. The samples were photographed and printed on $7 \times 10$-cm paper cards. The 89 samples were randomly presented to the participants.

\section{Participants}

Seventeen participants, all regular consumers of the product category, took part in this study. Participants ranged in age from 18 to 30 years ( 8 women and 9 men). The consumers were recruited from a university, on the basis of their interest and availability to participate the research. Only those consumers showing a shopping frequency higher than once a week were recruited. Participants were recruited on the basis of their consumption pattern; they all consumed dairy products such as milk, yoghurt and yoghurt drink at least once a week. Thus, one can assume that the participants were familiar with most dairy product packaging. Consumer tests were carried out in a lecture room at the university.

The participants were randomly divided in two groups of eight versus nine people, each of which evaluated the 89 samples using one of the proposed consumer profiling methods: categorization and perceptual mapping.

\section{Methodology}

Consumers had to complete the task; in both cases, the task needed to be completed in approximately $30 \mathrm{~min}$.

Categorization task. During the session, participants were first offered a list of 21 different impressions that the packaging samples may communicate about the product with the aid of packaging design, such as 'organic', 'fair trade', 'light' and 'tasty'. The list was based on appearance attributes of dairy product packaging. To construct the list, a search for terms was performed by the researcher based on all packaging design cues (i.e. material, image, colour, text and layout graphic design). Next to that, a list of appearance attributes retrieved from previous studies was deliberated to complete the list with impressions. ${ }^{17,20,27}$ Finally, a meeting with two industrial designers, one specialized in management of new product development and the other specialized in graphic and structural packaging design, was undertaken to check the validity of the list with impressions.

First, participants were asked to go through the list of impressions carefully. When ready, they were asked to categorize all products based on packaging design with the aid of the list with impressions. The impressions were presented to the participants in random order. The participants had the option to describe a group with more than one impression. Further, they had the opportunity to categorize one or more samples as 'different' when categorizing seemed impossible. At the end, the participants had to describe why the packaging samples have been categorized as such.

Perceptual mapping. Participants were asked to sort the samples into groups based on perceived similarity between products based on packaging design and to provide words that could describe each group. Consumers were instructed to complete the task according to their own criteria and that no right or wrong answers exist. As was the case for the participants performing the categorizing task, a package can be labelled as 'different'. Also for this methodology, at the end, participants were asked to write why the samples were grouped together in a certain group.

For both the categorizing and the perceptual mapping task, participants were asked to sort the products based on packaging design and not of, for instance, the product, opening system or ease of 
use. However, as stated earlier, one cannot ensure that variables such as previous experiences regarding ease of use have no effect on consumers' perception of products based on packaging design.

\section{Statistical analysis}

As a start of the analysis, the average number of impressions that was mentioned by participants was determined. In addition, hierarchical cluster analysis was performed to identify groups of products with similar impressions. Ward's aggregation method was applied. Chi-square was calculated to see how the packaging was perceived by the participants. Using the participants' descriptions of products (based on predefined vs own criteria) in terms of impressions, the products received a 'generalized' impression.

Multidimensional scaling (MDS) was performed to build a mapping of product from a proximities matrix (similarities or dissimilarities) between the scores individuals gave the products. In MDS, objects are represented as points in an $n$-dimensional space, such that the distances between the points match the observed dissimilarities as closely as possible. Kruskal's stress shows the relationship between dissimilarities and distances. The smaller the statistical stress, the better. ${ }^{40}$

From the MDS plots and cluster analysis, the products that were close together and were sorted in the same group received the same label. The perceptual maps of the MDS were used to analyse the relationship between packaging design cues and the impressions by comparing the different mappings of perceptions and packaging designs.

At the end, the researcher assessed the consumers' descriptions of perception influencing cues. The number of descriptions provided by each participant was counted. Next to that, the average number of descriptions was determined. This procedure was adopted for both categorizing task and perceptual mapping. All data analyses were performed using XLSTAT.

\section{RESULTS AND DISCUSSION}

\section{Categorizing task}

For the categorizing task, participants came up with an average of 2.6 impressions per product/packaging category. The minimum number of impressions was 2 and the maximum 4 . The relatively large number of words suggests that consumers had a clear representation of the stimulus.

As shown in Table 1, the statistical stress of the configuration for milk, yoghurt and yoghurt drink was on average 0.30 and thus sufficient. ${ }^{40}$

Hierarchical cluster analysis was useful for providing information about the impressions' relationships in consumers' minds. ${ }^{41}$ As shown in Figure 1, 89 samples were categorized into seven predominant clusters/impressions. As shown in Table 2, these clusters are 'biological/natural', 'ecological/fair trade', 'tasty/pleasurable', 'pure/old-fashioned', 'light', 'trust' and 'other'. Subsequently, MDS shows the two-dimensional perceptual map and indicates that milk packaging was separated into five groups, yoghurt packaging in six groups and yoghurt drink in four groups (Table 2). Figure 2 shows the clusters for the product category milk, Figure 3 for the product category yoghurt and Figure 4 for the product category yoghurt drink.

For milk packaging, an overlap is found between the impressions 'trust', 'pure/old-fashioned' and 'biological/natural'. This indicates that there is no clear or striking distinction between those impressions for this product group. Comparable findings apply for the product group yoghurt; in this case,

Table 1. Kruskal's stress per product category for the categorization task versus perceptual mapping task.

\begin{tabular}{lcc}
\hline & \multicolumn{2}{c}{ Kruskal's stress } \\
\cline { 2 - 3 } Product group & Categorization task & Perceptual mapping task \\
\hline Milk & 0.31 & 0.23 \\
Yoghurt & 0.27 & 0.24 \\
Yoghurt drink & 0.29 & 0.23 \\
\hline
\end{tabular}




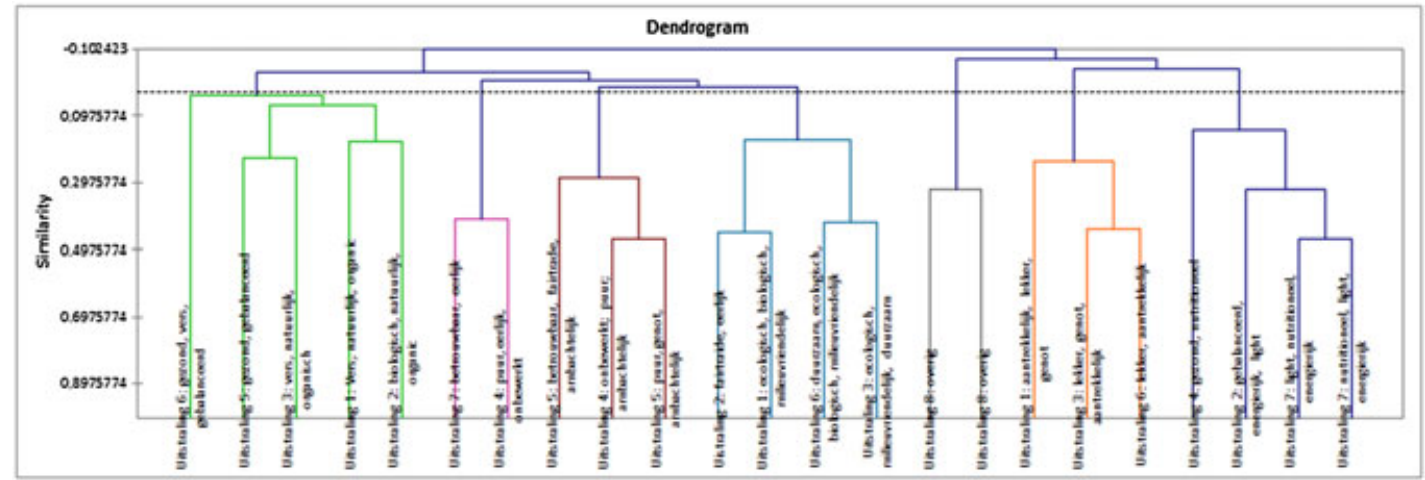

Figure 1. Cluster analysis of the impressions observed in the categorizing task.

Table 2. Impressions per product category in the categorizing task.

\begin{tabular}{lccc}
\hline Impression & Milk & Yoghurt & Yoghurt drink \\
\hline 1. Biological/natural & Yes & Yes & Yes \\
2. Ecological/fair trade & Yes & Yes & - \\
3. Tasty/pleasurable & - & Yes & Yes \\
4. Pure/old-fashioned & Yes & Yes & Yes \\
5. Light & Yes & Yes & Yes \\
6. Trust & Yes & Yes & - \\
\hline
\end{tabular}

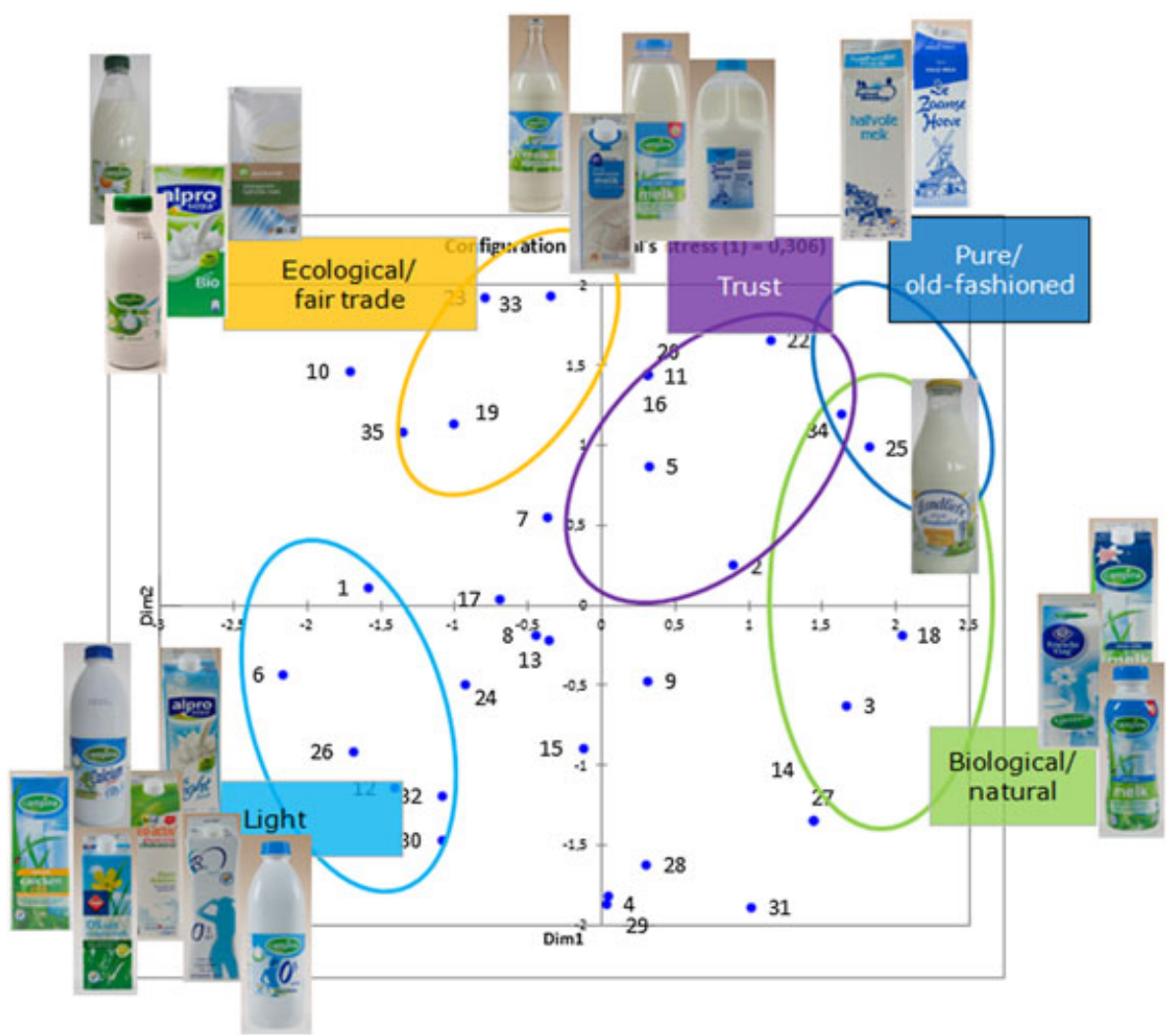

Figure 2. Perceptual map product category milk in the categorizing task (Kruskal's stress $=0.30$ ). 


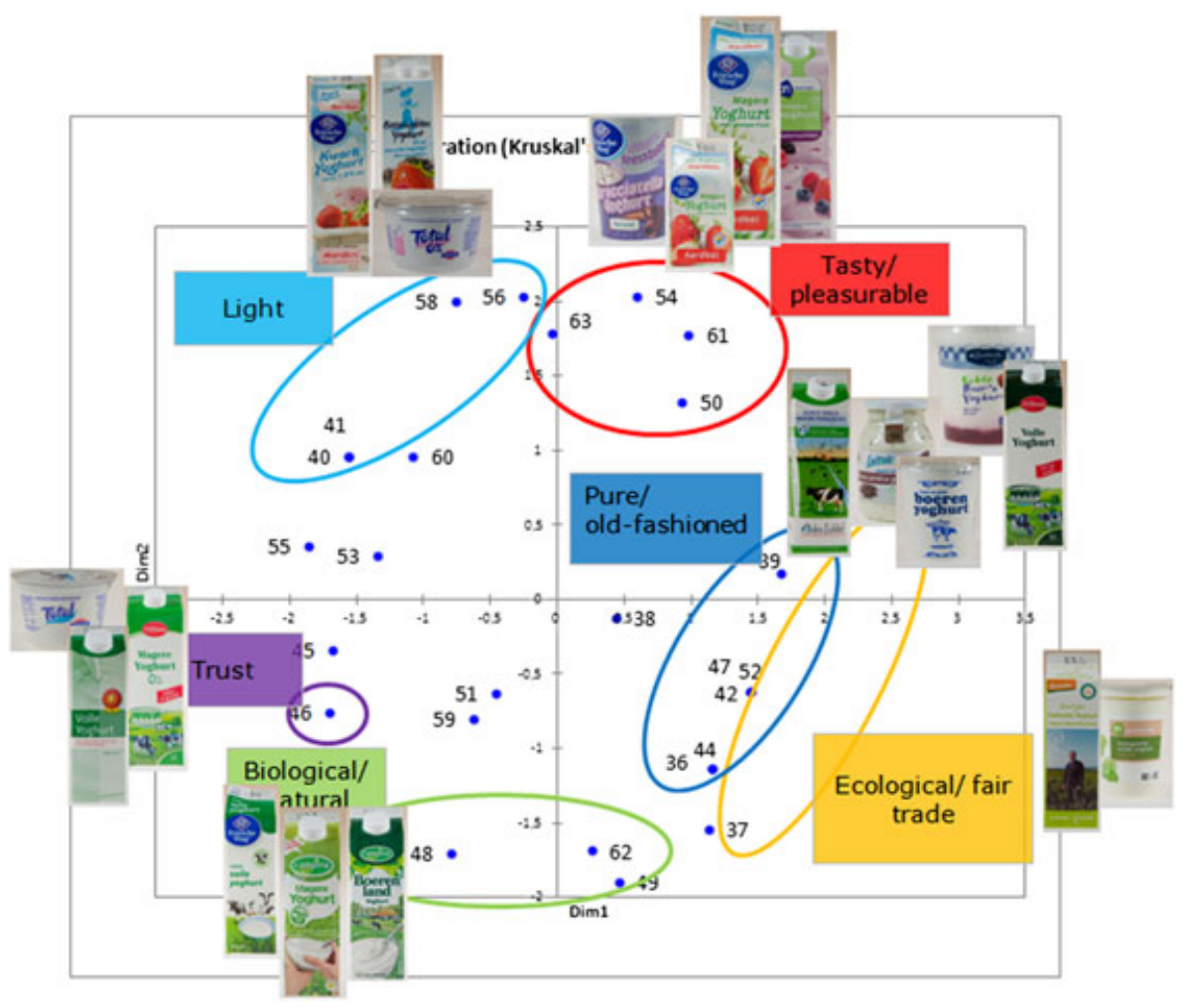

Figure 3. Perceptual map product category yoghurt in the categorizing task (Kruskal's stress $=0.27$ ).

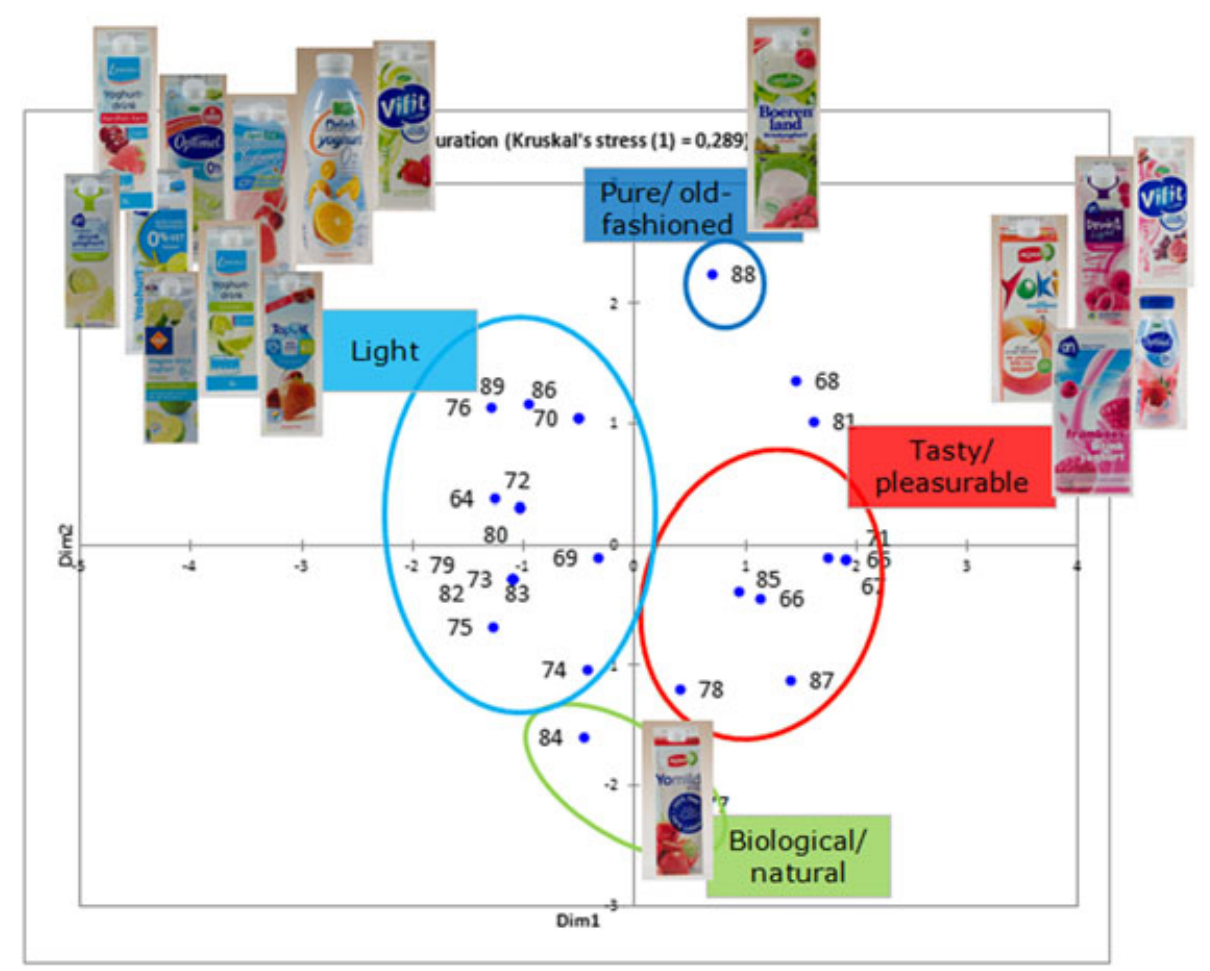

Figure 4. Perceptual map product category yoghurt drink in the categorizing task (Kruskal's stress $=0.29$ ). 
there is no clear distinction between the impressions 'pure/old-fashioned' and 'ecological/fair trade'.

Participants did not perceive milk products as tasty or pleasurable. For yoghurt and yoghurt drink, only product packaging that communicated a certain 'flavour' was perceived as tasty by the participants.

Participants divided yoghurt drink into only four impressions. The explanation for this may be that yoghurt drink is a relatively new product category with only few product variants of this category available in the Dutch supermarkets.

Furthermore, from the two-dimensional perceptual map, it can be seen that packaging cues that strongly influenced consumer perception were colour, layout and image. This suggests that these packaging cues might be the most relevant cues that influence the way consumers perceive dairy products. However, inconspicuous cues ensuing from, for example, typography, shape or material of the package make the difference between the impressions where an overlap is found ${ }^{42}$; such cues are not explicitly perceived by the participants, as is often the case for colour or images. The packaging cues brand, health logos and text seem to have relatively little influence on how products were perceived. For example, four packaging of the brand Campina with the same graphical layout were placed in two different groups; for the product group milk, 5 of 21 packaging were perceived as 'light' and 'fair trade' based on the text of the package.

Table 3 shows the resulting categories as well as some examples of individual words given by participants. Nine categories were mentioned by more than $10 \%$ of the consumers. The explanations that participants gave per impression were mainly related to colour and lay out as these packaging cues are often explicitly perceived by participants. ${ }^{42}$

Yet, the importance of the packaging cues colour, layout and image has been reported by other authors. ${ }^{6,43}$ These packaging cues might be important in influencing consumer purchase intention and finally purchase decisions. However, it is important to note that the perceptibility of these 'dominant' cues may strongly depend on the presence and obtrusiveness of any other cues. In other words, the distinguishing character is more important than the presence itself. As a consequence, for packaging designers it is well-nigh impossible to deduce design rules based on the cues that are unequivocal, transparent and deterministic.

\section{Perceptual mapping}

Participants listed an average of 3.5 impressions per group in the perceptual mapping task. The minimum number of impressions was 3 and the maximum was 5. The minimum, maximum and average numbers of impressions were slightly higher than those for the categorization task. This suggests that participants have slightly more options to describe the differences between the groups according to their own criteria.

As shown in Table 1, the statistical stress of the configuration for milk, yoghurt and yoghurt drink was 0.25 on average, and thus sufficient. ${ }^{40}$

Cluster analysis showed (Figure 5; Table 4) that participants categorized the 89 packaging into six clusters/impressions: 'tasty', 'healthy milk', 'biological', 'healthy/tasty', 'cheap' and 'luxury/traditional'.

Table 3. Categories mentioned by the participants in the categorization task to describe impressions (frequency and average order in which they were listed).

\begin{tabular}{llr}
\hline Category & \multicolumn{1}{c}{ Examples } & Frequency $(\%)$ \\
\hline Colour & Fresh colours, blue, light colours, no use of bright colours & 33 \\
Shape & Feminine shape, round shape, many shapes & 7 \\
Image/picture/drawing & Image of grass, fruit, cows, glass of milk & 12 \\
Layout packaging & Simple, clean, boring design not fresh looking, cheap, not tasty & 22 \\
Typography & Old-fashioned typography, strange typography, many different & 8 \\
Packaging material/shape & $\quad$ typographies used & 6 \\
Text & Glass, PET, transparent material & 9 \\
Incongruency & Texts such as 'calcium', 0\% fat, little use of text & 2 \\
& Packaging does not fit within product category, colour does not & \\
\hline
\end{tabular}




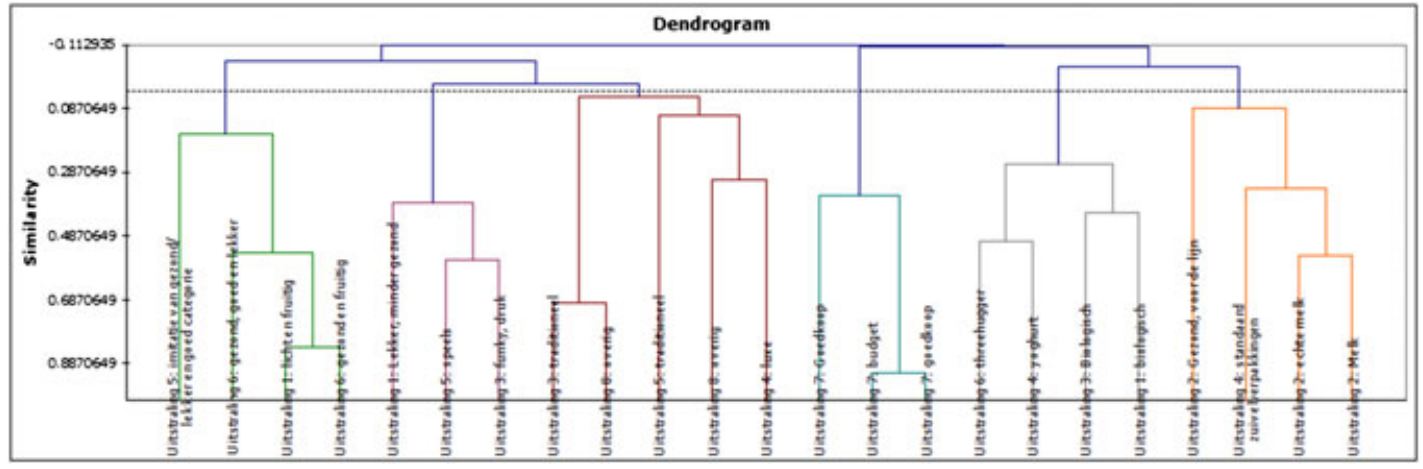

Figure 5. Cluster analysis of the impressions observed in the perceptual mapping task.

Table 4. Impressions per product category in the perceptual mapping task.

\begin{tabular}{lccc}
\hline Impression & Milk & Yoghurt & Yoghurt drink \\
\hline 1. Tasty & - & - & Yes \\
2. Healthy milk & Yes & - & - \\
3. Biological & Yes & Yes & Yes \\
4. Healthy/tasty & - & Yes & Yes \\
5. Cheap & Yes & Yes & Yes \\
6. Luxury/traditional & Yes & Yes & - \\
\hline
\end{tabular}

Figure 6 shows the clusters for the product category milk, Figure 7 for the product category yoghurt and Figure 8 for the product category yoghurt drink.

The impressions 'biological' and 'tasty' described by the participants were similar to the impression list that was supplied to participants in the categorization task. The impressions 'healthy milk', 'healthy/tasty', 'cheap' and 'luxury/traditional' were different than those of the categorizing task. Next to that, the impressions mentioned by the participants themselves do not overlap and have a clear distinction, different from the categorizing task.

As was the case in the categorizing task, the two-dimensional map showed that the packaging cues colour, image and layout influenced consumer perception of dairy products the most. Brand, health logos and text seemed to have relatively little influence. The most frequent cues mentioned by the participants can be found in Table 5 .

\section{Comparison}

In comparing the results from the categorization task and from the perceptual mapping task, the packaging listed in the same groups appeared to be quite similar for only two impressions (Figure 9).

The criteria of the perceptual mapping task described by the consumers were different than the researcher had taken into account for the categorizing task. The results of the categorizing task were strongly dependent on the predefined attributes selected for the study. For example, the researcher had not taken into account 'negative' impressions such as 'cheap' in the impression list. During the perceptual mapping task, participants judged some of the packaging as cheap. The predefined impressions of the categorization task may reflect more how marketers and designers perceive products appearance and not how consumers perceive it. ${ }^{33,44}$

The impressions mentioned by participants in the perceptual mapping task were simple and concrete. Because consumers have less experience in formally describing products/packaging, experts usually describe products at a more abstract level. ${ }^{45}$

Regarding the design of dairy packaging, information provided by the perceptual mapping task might provide more objective and realistic insight in how consumers perceive products based on packaging design. ${ }^{34}$ Consumers see less difference between packaging in terms of ecologic, fair trade, 


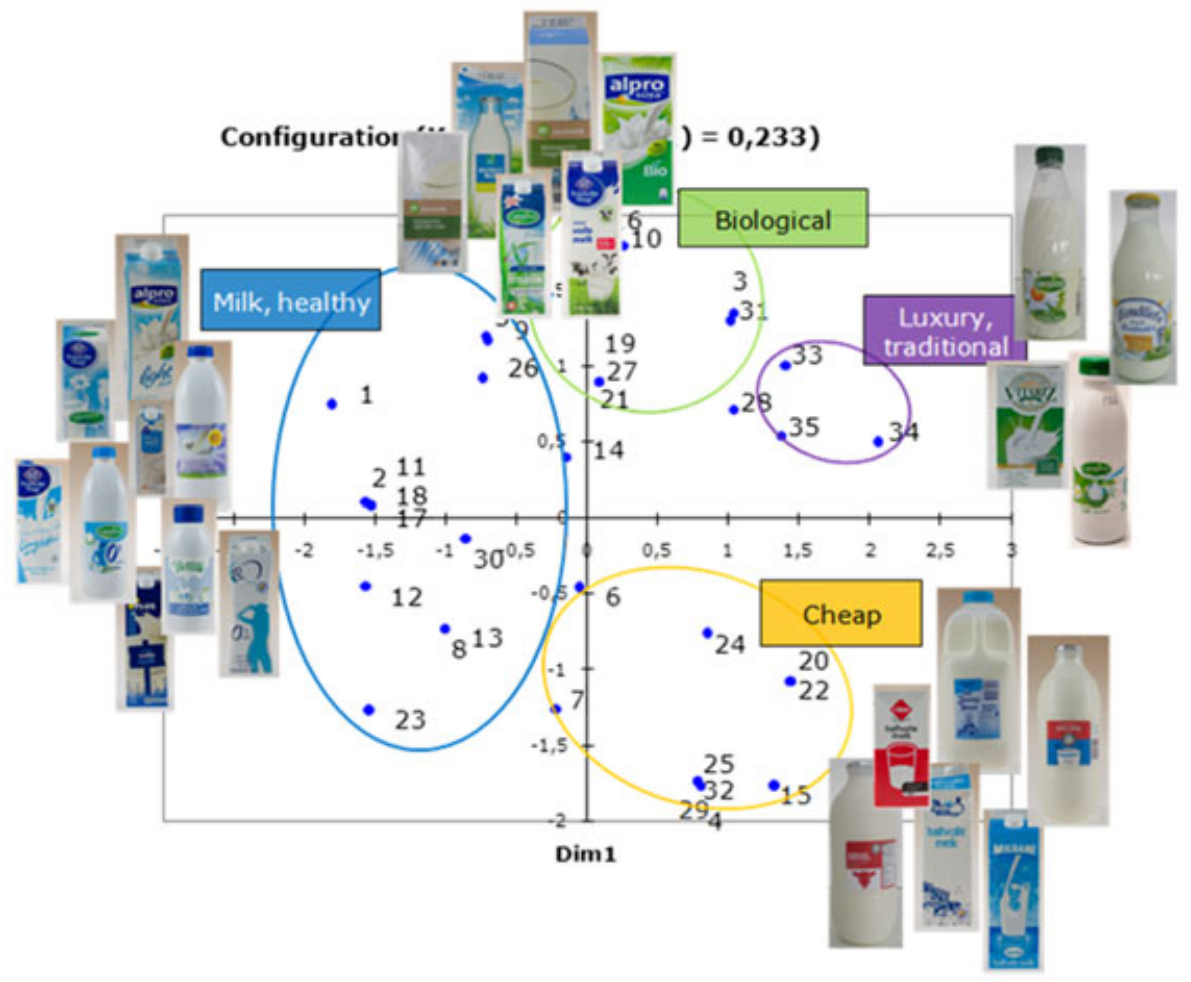

Figure 6. Perceptual map product category milk in the perceptual mapping task (Kruskal's stress $=0.23$ ).

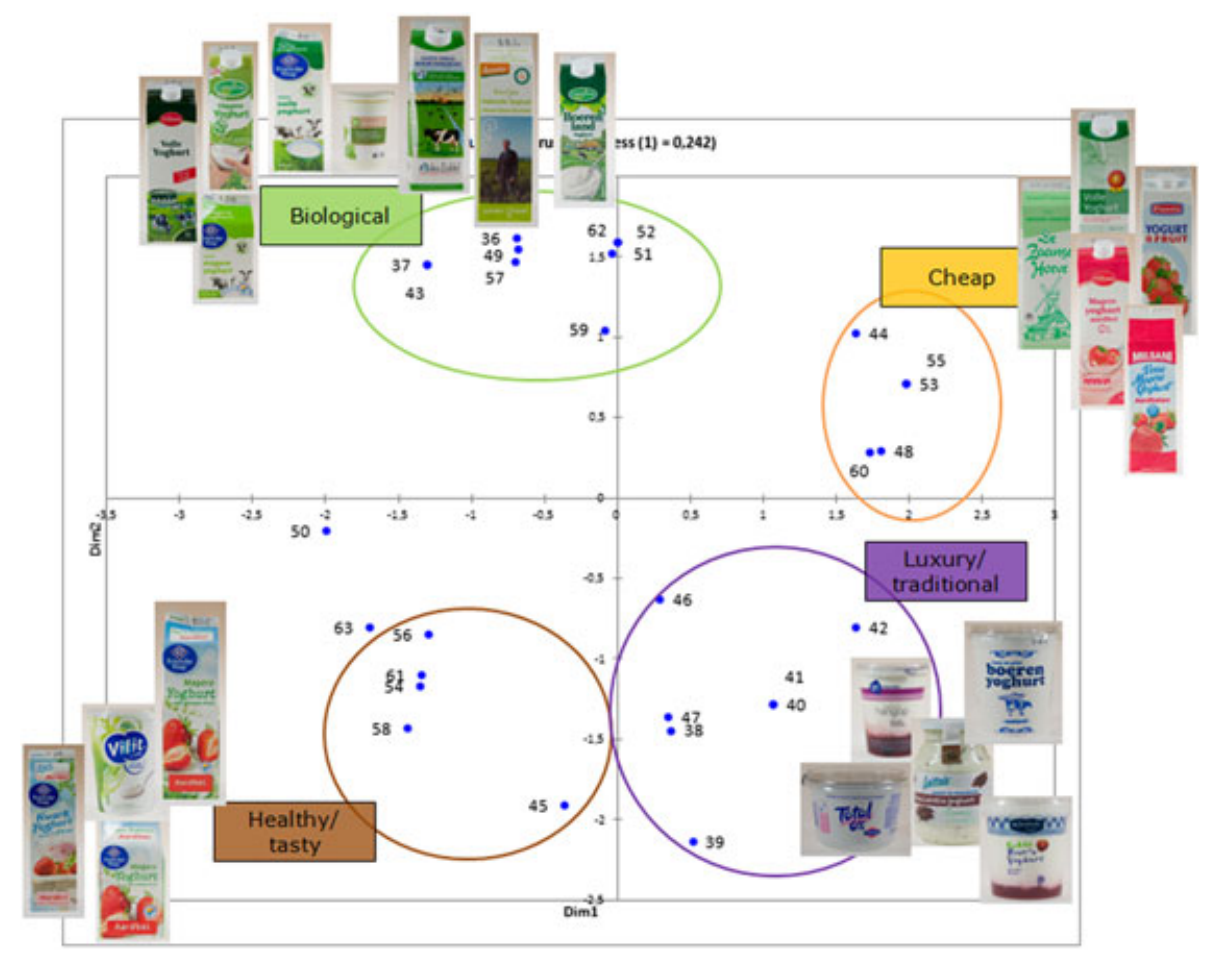

Figure 7. Perceptual map product category yoghurt in the perceptual mapping task (Kruskal's stress $=0.24$ ). 


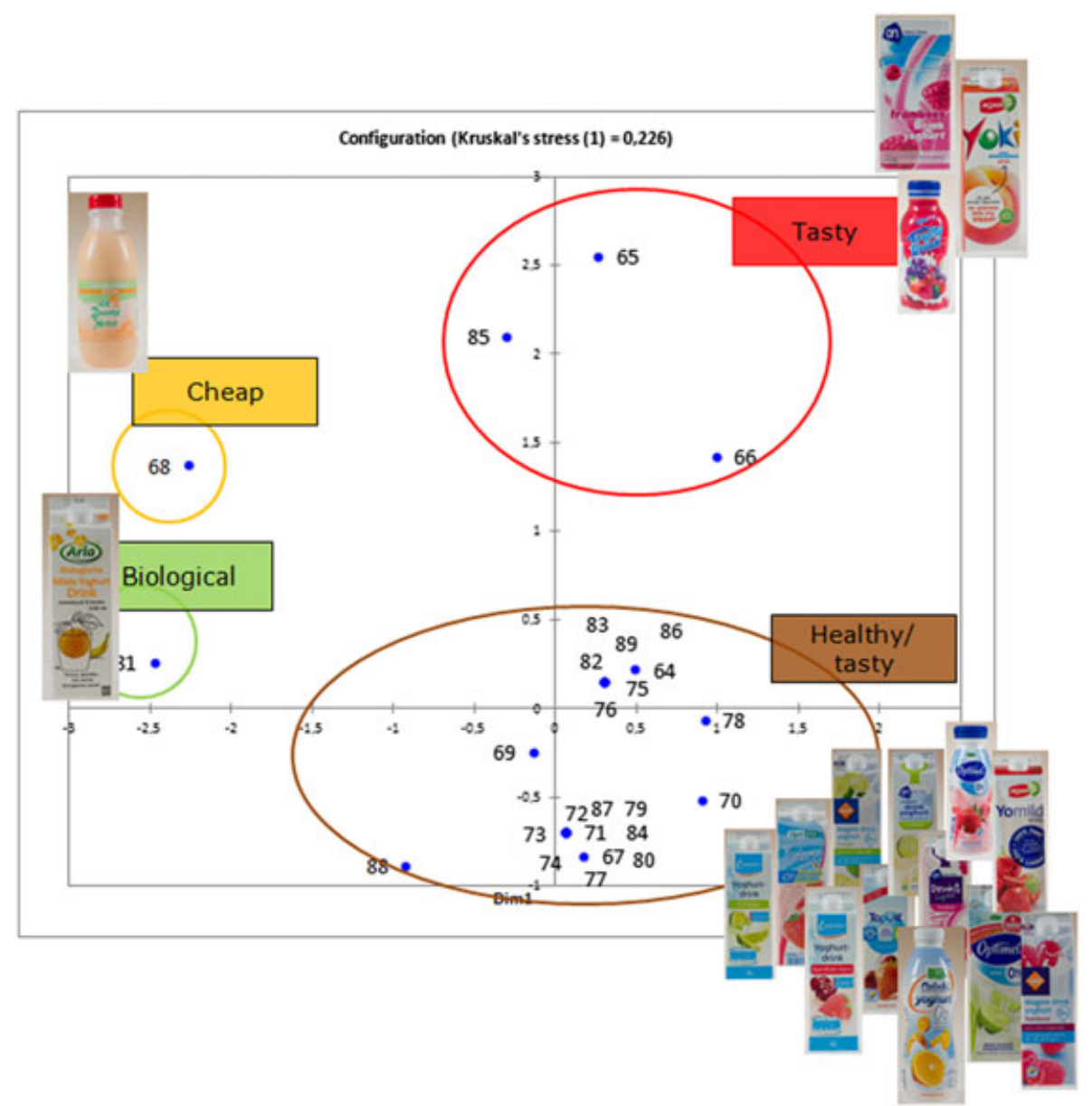

Figure 8. Perceptual map product category yoghurt drink in the perceptual mapping task (Kruskal's stress $=0.23$ ).

biological, pure and natural, for example. Consumers use catch-all terms to describe how they perceive products by packaging designs. However, when asking them which packaging communicates that products are ecologic, fair trade, biological, pure and natural, they are able to differentiate between those impressions. ${ }^{34}$ Furthermore, as consumers are less knowledgeable about design language, the exact and formal interpretation of these terms/impressions may be less clear. This suggests that predefined terms/impressions might need to be treated with caution in describing how consumers perceive products based on packaging design by themselves. ${ }^{45,46}$ This again supports the opinion that identified packaging cues and any terms/impressions cannot directly be used as the basis for design rules.

Table 5. Categories mentioned by the participants in the perceptual mapping task to describe impressions (frequency and average order in which they were listed).

\begin{tabular}{llc}
\hline Category & \multicolumn{1}{c}{ Examples } & Frequency $(\%)$ \\
\hline Colour & Bright colours, many different colours, light colours, green & 30 \\
& natural colours & \\
Shape & Round shapes, traditional decoration, taut lines & 5 \\
Image/picture/drawing & Tasty pictures, nature, milk, fruit & 25 \\
Layout packaging & Simple, messy & 15 \\
Typography & Simple, playful typography, many different typographies used & 14 \\
Packaging material/shape & Standard shape, novel shape, glass & 8 \\
Text & 'fit', 'light', '0\% vet' & 3 \\
Opening & Traditional cap & 1 \\
\hline
\end{tabular}



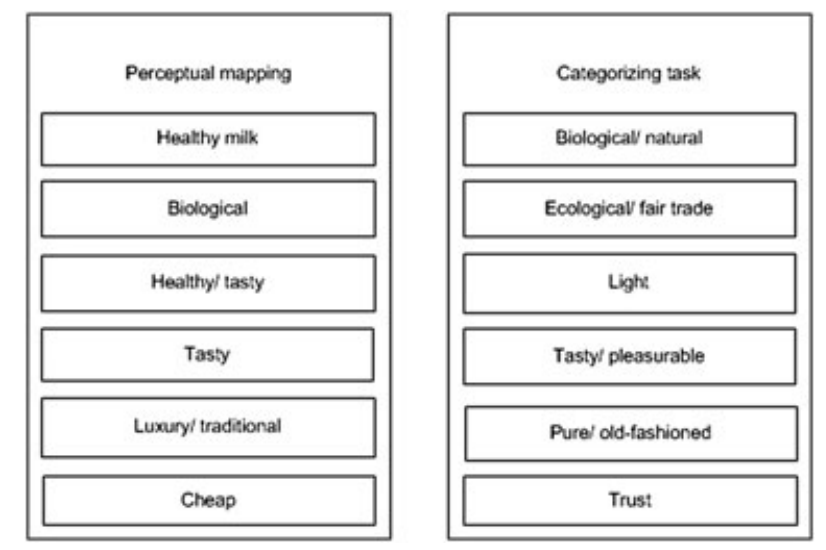

Figure 9. Impressions observed in the categorizing and perceptual mapping task.

\section{CONCLUSIONS}

In this publication, the methods 'categorizing' and 'perceptual mapping' have been compared as a means for the identification of explicit cues that affect consumer perception of dairy products on the base of packaging design. Both categorizing and perceptual mapping have been demonstrated to be useful, simple and user-friendly methods to determine the packaging design cues that influence the perception of dairy products. ${ }^{28,29}$

Perceptual mapping provided more subconscious perceptions than the categorizing task because consumers were asked to describe products based on packaging design according to their own criteria. The criteria that appeared in the perceptual mapping task were different than those that appeared in the categorizing task. In other words, the criteria described by the consumer were different than those the researcher had taken into account. This implies that the appearance attributes retrieved using the categorizing task do not give an objective and accurate overview of how consumers perceive products based on packaging design. ${ }^{33}$ Basing design decisions on demand-oriented methods in which predefined categories are presented to consumers to judge whether the intended meaning is perceived by consumers through the visual appearance of a package is highly subjective and provides unrepresentative information. ${ }^{47}$ The use of these types of research methods clarifies why many product packaging combinations fail, among others. ${ }^{28-31}$ Perceptual mapping fosters understanding of the potential for product packaging to be misinterpreted.

Ultimately, the goal of the research is to support packaging designers in developing packages that better align with consumer perception. In other words, if packages are designed adequately, more effective communication via packaging design is possible. In the search for design rules and guidelines, indications on relevant packaging cues can be extremely contributing.

As previously mentioned, however, formulating design guidelines based on consumers' views on product packaging formulated in terms of sheer cues is a risky undertaking, as it is the amalgamation of individual cues that render the overall perception. Therefore, no unequivocal and objective translation of cues into design rules is possible. Consequently, it is attempted to support designers by providing them with circumstantial mappings of perceptions versus groups of cues provided by perceptual mapping.

At the same time, an important issue in many of the packaging design processes for the different markets is that companies have to decide how to position their product and brand in the market. They can choose to either adapt to the typical characteristics of the competitive landscape or break free. Yet, this becomes a strategic decision that will give cause to more and different design decisions to be made.

Furthermore, more research is needed to investigate the influence of packaging design on consumer product perception. Variables such as previous experiences and personal characteristics are not included in this study. It would be valuable to understand to what extent these variables affect consumer product perception. Subsequently, more research is necessary to study the influence of packaging design on purchase intentions. 
Moreover, a large extent of everyday decision making is made without conscious awareness, especially for fast-moving consumer goods, where the degree of product involvement is very low. ${ }^{48,49}$ Thus, in supermarkets, consumer decision making is generally made with little attention and without effortful processing; subconscious information processing may often be able to predict food choice behaviour. ${ }^{50}$ In this respect, computer-simulated choice-based conjoint shopping, being a relatively new technique, can be of added value studying dynamic buying behaviour. When test persons can shop in a virtual supermarket that demonstrably resembles a real-life supermarket, the actual buying process can be simulated much more effective and efficient. Using virtual shopping can give marketers more insight in real-life decision making. It can reveal phenomena that underlie the actions of people, although these people are not capable of explicitly expressing the occasion or reason for their actions. Although it has not yet incontestably been proven that virtual reality provides a reliable and efficacious environment for simulation, it can certainly provide marketers with valuable insights as how respondents shop and what draws their preferences. The results of the research described in this publication will considerably contribute to the development of such a virtual reality simulation environment. In the future, the virtual reality shopping environment can be used together with fMRI, EEG or eye tracking to clarify the subject of consumer response (conscious versus subconscious) to product packaging design to help packaging developers to design products and packaging that are well noticed and well understood by consumers.

\section{REFERENCES}

1. Cardello AV. Consumer expectations and their role in food acceptance. In Measurement of Food Preferences, MacFie HJH, Thomson DMH (eds). Blackie Academic: London, 1994.

2. Imram N. The role of visual cues in consumer perception and acceptance of a food product. Nutrition and Food Science 1999; 5: 224-228.

3. Ares G, Deliza R. Indentifying important package features of milk desserts using free listing and word association. Food Quality and Preference 2010; 21: 621-628.

4. Hutchings JB. Sensory assessment of appearance methodology. In Food Colour and Appearance, Hutchings (ed.). Blackie Academic \& Professional: UK, 1994; 105-141.

5. Kostyla AS, Clydesdale FM. The psychophysica lrelationships between colour and flavour, CRC Critical Review. Food Science and Nutrition 1978; 10: 303-319.

6. Ampuero O, Vila N. Consumer perceptions of product packaging. Journal of Consumer Marketing 2006; 23(2): 100-112.

7. Prendergast PG, Pitt L. Packaging marketing, logistics and the environment: are there trade-offs? International Journal of Physical Distribution and Logistics Management 1996; 26: 60-72.

8. Rettie R, Brewer C. The verbal and visual components of package design. The Journal of Product and Brand Management 2000; 9: 56-70.

9. ten Klooster R. Packaging design. A methodological development and simulation of the design process. Ph.D. thesis, Delft University of Technology, 2002.

10. McDanie C, Baker RC. Convenience food packaging and the perception of product quality. Journal of Marketing 1977; 41: $57-58$.

11. Löfgren M. Winning at first and second moment of truth: an exploratory study. Managing Service Quality 2005; 15(1): $102-115$.

12. Hofmeyr J, Rice B. Commitment-led Marketing: The key to brand profits is in the customer's mind. John Wiley \& Sons Ltd: Chichester, England, 2002; 216.

13. Moskowitz HR, Reisner M, Lawlor JB, Deliza R. Packaging research in food product design and development. Wiley-Blackwell: Ames, 2009.

14. Young S. Winning at retail: research insights to improve the packaging of children's products. Young consumers: Insight and Ideas for Responsible Marketers 2004; 5: 17-22.

15. Olson JC, Dover PA. Disconformation of consumer expectations through product trial. Journal of Applied Psychology 1979; 64: 179-189.

16. Deliza R, MacFie HJH. The generation of sensory expectation by external cues and its effect on sensory perception and hedonic ratings: A review. Journal of Sensory Studies 1996; 11: 103-128.

17. Ares G, Deliza R. Studying the influence of package shape and colour on consumer expectations of milk dessert using word association and hard laddering. Food Quality and Preference 2010; 19: 636-643.

18. Durgee JF. Visual rhetoric in new product design. Advances in Consumer Research 2003; 30: 367-372.

19. Langley J, Turner N, Yoxall A. Attributes of packaging and influences on waste. Packaging Technology and Science 2010; 24: 161-175. DOI: $10.1002 /$ pts. 924

20. Grunert KG, Bech-Larsen T, Bredahl L. Three issues in consumer quality perception and acceptance of dairy products. International Dairy Journal 2000; 10: 575-584. 


\section{M. GELICI-ZEKO ET AL.}

21. Silayoi P, Speece M. Packaging and purchase decisions. British Food Journal 2004; 106: 607-608.

22. Raghubir P, Greenleaf EA. Ratios in Proportion: What Should the Shape of the Package Be? Journal of Marketing 2006; 70: 95-107.

23. Pittard N, Ewing M, Jevons C. Aesthetic theory and logo design: examining consumer response to proportion across cultures. International Marketing Review 2007; 24: 457-473.

24. Van Rompay TJL, Pruyn ATH, Tiek P. Symbolic meaning integration in design and its influence on product and brand evaluation. International Journal of Design 2009; 3: 19-26.

25. Bramklev C. On a proposal for a generic package development process. Packaging Technology and Science 2009; 22: 171-186. DOI: $10.1002 / \mathrm{pts} .850$

26. Cardello AV. Sensory evaluation and consumers food choices. Cereal Foods world 1995; 40(11): 876-878.

27. Ares G, Varela P, Rado G, Giminez A. Identifying ideal products using three different consumer profiling methodologies. Comparison with external preference mapping. Food Quality and Preference 2011; 22: 581-591.

28. Griffin A, Page A. PDMA success measurement project: recommended measures for product development success and failure. Journal of Product Innovation Management 1996; 13(6): 478-496.

29. ACNielsen. Product introducties: de feiten op een rij. ACNielsen Research: Amsterdam, 2000.

30. Blom C. Stretchen in de supermarkt. Een analyse van vijftig grote FMCG merken in de Nederlandse markt, 2005. SWOCC: Amsterdam.

31. Ellis SR. A psychometric investigation of a scale for the evaluation of the aesthetic element in consumer durable goods. Unpublished dissertation, University of Arizona, Tucson AZ, 1993.

32. Orth UR, Malkewitz K. Holistic package design and consumer brand impressions. Journal of Marketing 2008; 72(3): 64-81.

33. Krippendorf K. On the essential contexts of artifacts or on the proposition that 'design is making sense (of things)'. Design Issues 1989; 5(2): 9-39.

34. Hsu SH, Chuang MC, Chang CC. A semantic differential study of designers' and users' product form perception. International Journal of Industrial Ergonomics 2000; 25(4): 375-381.

35. Rosch E, Mervis CB, Gray WD, Johnson DM, Boyesbraem P. Basic objects in natural categories. Cognitive Psychology 1976; 8(3), pp. 382-439.

36. Donoghue S. Projective techniques in consumer research. Journal of Family Ecology and Consumer Sciences 2000; 28: $47-53$.

37. Schoormans J, Eenhuizen-van den Berge M, Van de Laar G, Van den Berg L. Designing packages that communicate product attributes and brand values: an exploratory method. The Design Journal 2010; 12: 31-47.

38. FAOSTAT. Mama waar komt de melk vandaan? Wake up call voor melkveesector én maatschappij. Wakker dier, 2010.

39. CBS. Productschap zuivel. Statistisch jaaroverzicht 2010—Hoofdstuk 4, 2010; 48.

40. Kruskal JB. Multidimensional scaling by optimizing goodness of fit to a nonmetric hypothesis. Pscychometria 1964; 29(1): $1-27$.

41. Hough G, Ferraris D. Free listing: A method to gain initial insight of a food category. Food Quality and Preference 2010; 21: 295-301.

42. Grunert KG, Wills JW. A review of European research on consumer response to nutrition information on food labels. Journal of Public Health 2007; 15: 385-399.

43. Deliza R, MacFie H, Hedderley D. An investigation using the repertory grid and focus group methods of the package features affecting consumer perception of fruit juice. Brazilian Journal of Food Technology 1999; 2: 63-71.

44. Chi MTH, Feltovich PJ, Glaser R. Categorization and representation of physics problems by experts and novices. Cognitive Science 1981; 5(2): 121-152.

45. Blijlevens J, Creusen MEH, Schoormans JPL. How consumers perceive product appearance: the identification of three product appearance attributes. International Journal of Design 2009; 3(3): 27-35.

46. Nordin N, Selke S. Social aspect of sustainable packaging. Packaging Technology and Science 2010; 23: 317-326. DOI: $10.1002 /$ pts.899

47. Schmitt B, Simonson A. A Marketing aesthetics: the strategic management of brands, identity and image. The Free Press: London, UK, 1997.

48. Bargh JA. Losing consciousness: automatic influences on consumer judgement, behaviour and motivation. Journal of Consumer Research 2002; 29: 280-285.

49. Fitzsimons GJ, Hutchinson JW, Williams P. Non-conscioius influences on consumer choice. Marketing Letters 2002; 13: 269-279.

50. Pelsmacker P, Geuens M, van den Bergh J. Foundations of Marketing Communications. Prentice Hall, Financial Times: London, 2005. 